\title{
Production of a biodiesel-like biofuel without glycerol generation, by using Novozym 435, an immobilized Candida antarctica lipase
}

\author{
Carlos Luna', Cristóbal Verdugo ${ }^{2}$, Enrique D Sancho ${ }^{3}$, Diego Luna ${ }^{1,4^{*}}$, Juan Calero ${ }^{1}$, Alejandro Posadillo ${ }^{4}$,
} Felipa M Bautista ${ }^{1}$ and Antonio A Romero ${ }^{1}$

\begin{abstract}
Background: Novozym 435, a commercial lipase from Candida antarctica, recombinant, expressed in Aspergillus niger, immobilized on macroporous acrylic resin, has been already described in the obtention of biodiesel. It is here evaluated in the production of a new biofuel that integrates the glycerol as monoglyceride (MG) together with two fatty acid ethyl esters (FAEE) molecules by the application of 1,3-selective lipases in the ethanolysis reaction of sunflower oil.

Results: Response surface methodology (RSM) is employed to estimate the effects of main reaction. Optimum conditions for the viscosity, selectivity, and conversion were determined using a multifactorial design of experiments with three factors run by the software Stat Graphics version XV.I. The selected experimental parameters were reaction temperature, oil/ethanol ratio and alkaline environment. On the basis of RSM analysis, the optimum conditions for synthesis were $1 / 6 \mathrm{oil} / \mathrm{EtOH}$ molar ratio, $30^{\circ} \mathrm{C}$, and $12.5 \mu \mathrm{l}$ of $\mathrm{NaOH} 10 \mathrm{~N}$ aqueous solutions, higher stirring than $300 \mathrm{rpm}$, for $2 \mathrm{~h}$ and $0.5 \mathrm{~g}$ of biocatalyst.
\end{abstract}

Conclusions: These obtained results have proven a very good efficiency of the biocatalyst in the studied selective process. Furthermore, it was allowed sixteen times the successive reuse of the biocatalyst with good performance.

Keywords: Biodiesel; Enzyme biocatalysis; Candida antarctica lipase B (CALB); N435; Response surface methodology; Transesterification

\section{Background}

Currently, fossil fuel is globally the main primary source of energy. However, as its availability is becoming increasingly limited, it is accepted and assumed that the era of cheap and easily accessible fossil fuel is coming to its end. Thus, the production of biodiesel from renewable raw materials has become very important in recent years as a potential alternative to partially satisfy the future energy demands in the transport sector [1,2].

In this respect, transesterification is currently the most attractive and widely accepted methodology used for biodiesel production [3]. This usually involves the use of homogeneous base catalysts operating under mild

\footnotetext{
* Correspondence: qo1lumad@uco.es

${ }^{1}$ Department of Organic Chemistry, University of Cordoba, Campus de

Rabanales, Bldg. Marie Curie, 14014, Cordoba, Spain

${ }^{4}$ Seneca Green Catalyst S.A., Bldg Centauro, Technological Science Park of

Cordoba, Rabanales XXI, 14014, Córdoba, Spain

Full list of author information is available at the end of the article
}

conditions. In order to shift the equilibrium towards the production of fatty acid methyl esters (FAME), an excess of methanol is normally utilized in the process to produce biodiesel. However, glycerol is always produced as a contaminant in addition to alkaline impurities that need to be removed. The glycerol by-product is the main drawback of this method because it lowers the overall efficacy of the process and its removal requires several consecutive water washing steps and hence creates a demand for a lot of water $[4,5]$.

A series of alternative methods are being investigated to avoid the problems associated with the generation of glycerol in the conventional process. They all are based on achieving various glycerol derivatives in the same transesterification process. In this way, the complex and expensive additional separation process of glycerol is eliminated and the overall yield of the process increased. These novel methodologies are able to prepare methyl 
esters of fatty acids from lipids using different acyl acceptors instead of methanol in the transesterification process that result in glycerol derivatives as co-products [6]. For example, the transesterification reaction of triglycerides with dimethyl carbonate (DMC) [7], ethyl acetate [8], or methyl acetate [9] generates a mixture of three molecules of FAME or fatty acid ethyl esters (FAEE) and one of glycerol carbonate (GC) or glycerol triacetate (triacetin). These mixtures, including the glycerol derivative molecules, have physicochemical properties similar to biodiesellike biofuel [10]. In the present case, the atom efficiency is also improved because the total number of atoms involved in the reaction is obtained in the final mixture.

On the other hand, we have recently developed a protocol for the preparation of a new biodiesel-like biofuel, which integrates glycerol into monoglycerides via 1,3regiospecific enzymatic transesterification of sunflower oil using free [11] and immobilized [12-14] porcine pancreatic lipase (PPL). The operating conditions of such enzymatic process were more efficient compared to the preparation method of conventional biodiesel and did not generate any acidic or alkaline impurities. Thus, the Ecodiesel biofuel [12-15] obtained through the partial ethanolysis of triglycerides with 1,3-selective lipases is constituted by a mixture of two parts of FAEE and one of monoacylglyceride (MG). These glycerol derivative MGs are soluble components in the FAEE mixture suitable for use as a biodiesel-like biofuel. In the current case, ethanol was used as a cheap reagent, instead of the more expensive substrates such as dimethyl carbonate or methyl acetate. This procedure takes advantage of the 1,3-selective nature of the most known lipases, which allows to terminate the process in the second step of the alcoholysis to yield the mixture of $2 \mathrm{~mol}$ of FAEE and $1 \mathrm{~mol}$ of MG as products (Figure 1). In this way, the glycerol is kept in the form of monoglyceride, which avoids the production of glycerol as by-product, reducing the environmental impact of the process.

In summary, the enzymatic process to obtain this biodiesel-like biofuel operates under much smoother conditions, impurities are not produced, and the biofuel produced exhibits similar physicochemical properties to those of conventional biodiesel. Last but not least, MGs enhance biodiesel lubricity, as it was demonstrated by recent studies [16-18]. Besides, the ethanol that is not spent in the enzymatic process remains in the reaction mixture, and the blend obtained after the reaction can be used directly as fuel. In this respect, very recent studies [19-21] have shown that blends of diesel fuel and biodiesel containing ethanol reduce power output slightly than regular diesel. No significant difference in the emissions of $\mathrm{CO}_{2}$, $\mathrm{CO}$, and $\mathrm{NO}_{x}$ between regular diesel and biodiesel or ethanol and diesel blends was observed. Furthermore, the use of these blends resulted in a reduction of particulate matter. Consequently, such blends can be used in a diesel engine without any modification despite the slightly reduced power output compared to pure diesel. Thus, the Ecodiesel is currently utilized as a blend of fatty acid alkyl esters with ethanol, alone or with any proportion of diesel fuel $[21,22]$.

The high cost of traditional industrial lipases restricted their use in biofuel production, but the current availability of the recombinant purified in sufficiently high quantities has helped to achieve the economic viability as the crucial factors affecting productivity of enzymatic biodiesel synthesis are the suitable raw materials and the selected lipase. The stability and catalytic efficiency of the latter can be improved by optimizing reaction conditions such as substrate concentrations, temperature, water activity, and alkaline concentration of the enzyme's microenvironment [23]. In this respect, although Ecodiesel was initially obtained using pig pancreatic lipases (PPL), remarkable results have been also obtained with a low-cost purified microbial lipase, Lipopan 50 BG (Novozymes A/S, Bagsværd, Denmark) [15], from Thermomyces lanuginosus microorganism, usually used as bread emulsifier (bread improver) [24]. To our knowledge, this lipase has not been described as a biocatalyst in any chemical process. The application of an available lipase on an industrial scale is a significant<smiles>[R]C(=O)OCC(COC([R])=O)OC([Y])CCO</smiles>

Figure 1 Representative scheme of Ecodiesel production by application of 1,3-selective enzymatic catalysis. 
approximation to get an economically feasible biofuel production by enzymatic method. However, this lipase has a main drawback: it cannot be reused, since the purified lipase extract is meant to be in a soluble form.

The aim of the present study is to evaluate Novozym 435, a commercial lipase from Candida antarctica, recombinant (CALB), expressed in Aspergillus niger and immobilized onto an acrylic macroporous resin [25]. Novozym 435 has previously been used in the synthesis of conventional biodiesel as well as in other transesterification processes such as interesterification [26] and in lipase-catalyzed biodiesel production by isopropanolysis of soybean oil [27]. In this respect, Novozym 435 is also described very recently in lipase-catalyzed simultaneous biosynthesis of biodiesel and glycerol carbonate, by using dimethyl carbonate as acyl acceptor to obtain a biodiesel-like biofuel without glycerol generation [28]. Thus, in this study, it is intended to put in value the 1,3-selective behavior of these commercial lipases to make feasible the profitable production of alternative biofuels [5], using an enzymatic approach.

\section{Methods}

In this respect, in order to evaluate the influence of crucial parameters (lipase amount, temperature, oil/ethanol volumetric relationship, and alkaline environment) in the transesterification reaction, a multifactorial design of experiments and response surface methodology (RSM) using a multifactorial design of experiments with three factors run by the software Stat Graphics version XV.I were used. This study has been developed to optimize the catalytic behavior of this 1,3-selective lipase (N435) in the partial ethanolysis of sunflower oil, to obtain a biofuel that integrates glycerol as MG together with the different FAEEs in the enzymatic ethanolysis process as well as with the excess of unreacted ethanol. This biofuel mixture currently named Ecodiesel is able to directly operate diesel engines, alone or in whichever mixture with diesel fuel, without anymore separation or purification process.

Commercial sunflower oil was locally obtained. The chromatographically pure ethyl esters of palmitic acid, stearic acid, oleic acid, linoleic acid, and linolenic acid were commercially obtained from AccuStandard (New Haven, CT, USA), and hexadecane (cetane) was obtained from Sigma-Aldrich (St. Louis, MO, USA). Other chemicals like absolute ethanol and sodium hydroxide were pure analytical compounds (99.5\%) obtained commercially from Panreac (Castellar Del Valles, Spain). Novozym 435, the lipase B from C. antarctica (CALB), was kindly provided by Novozymes A/S. This commercial lipase is produced by submerged fermentation of a genetically modified A. niger microorganism and adsorbed on a macroporous acrylic resin. The specific activity of this commercial lipase in the hydrolysis of tributyrin was $3,000 \mathrm{U} / \mathrm{g}$.
In this respect, additional experiments were conducted with a pure lipase B from C. antarctica, recombinant from Aspergillus oryzae, powder, from Sigma-Aldrich. The specific activity of this commercial lipase in the hydrolysis of tributyrin was $>1,000 \mathrm{U} / \mathrm{g}$. In this way, the existence of possible differences in the catalytic behavior of CALB lipases by the influence of the support could be detected.

\section{Results and discussion \\ Comparative chromatograms of standardized reaction products}

To identify the most characteristic components of biofuels obtained by enzymatic alcoholysis, as well as to compare their rheological properties, several commercial standards of reference for FAME, FAEE, MG, and triacylglycerol (TG) were used, as shown in Figure 2. Here, a representative sample of monoglycerides of sunflower oil is also included, which was easily achieved by the substitution of methanol or ethanol by glycerol, in a conventional alcoholysis process with $\mathrm{KOH}$ as homogeneous catalyst following standard experimental conditions.

Here, we can see that the different esters of fatty acids (FAEs), which compose the lipid profile of the sunflower oil, display retention times (RTs) slightly higher than those of cetane ( $n$-hexane) used as internal standard. Thus, whereas RT of cetane is around $10 \mathrm{~min}$, all RTs of FAEs appear in the range of 16 to $26 \mathrm{~min}$. These are composed of methyl, ethyl, and glycerol esters (the latter constitute MGs) of palmitic, stearic, linoleic, and oleic acids. Thus, palmitic acid (C16:0) derivatives are grouped in a narrow range of RT, 16 to $17 \mathrm{~min}$. Derivatives of oleic $(\mathrm{C} 18: 1)$ and linoleic acid (C18:2) are grouped in RT of 19 to $21 \mathrm{~min}$, with the exception of glycerol ester of oleic acid, or what is the same, the MG of the oleic acid has a different behavior, with a RT = $26 \mathrm{~min}$. Glycerol RT appears at $5 \mathrm{~min}$, before cetane. The absence of this compound in the obtained chromatograms clearly demonstrates the selective nature of the studied enzymatic transesterification reaction.

In Figure 2, the presence of diacylglycerol (DG) with higher retention times, 40 to $60 \mathrm{~min}$, can also be seen, which do not allow its integration into the GC chromatogram, so that it is necessary to determine DG together and TG by using an internal standard such as cetane here employed. It should be noted that the differences in RT values between MG and DG are much higher than those existing between MG and FAME or FAEE, such as it is expected by the differences between their corresponding molecular weights. At the same time, it is clear that the FAMEs, FAEEs, and MGs display somewhat higher RT values than cetane, but within the molecular weight range, which allows considering similar chemical-physical properties between the FAE and the hydrocarbons that constitute diesel. 


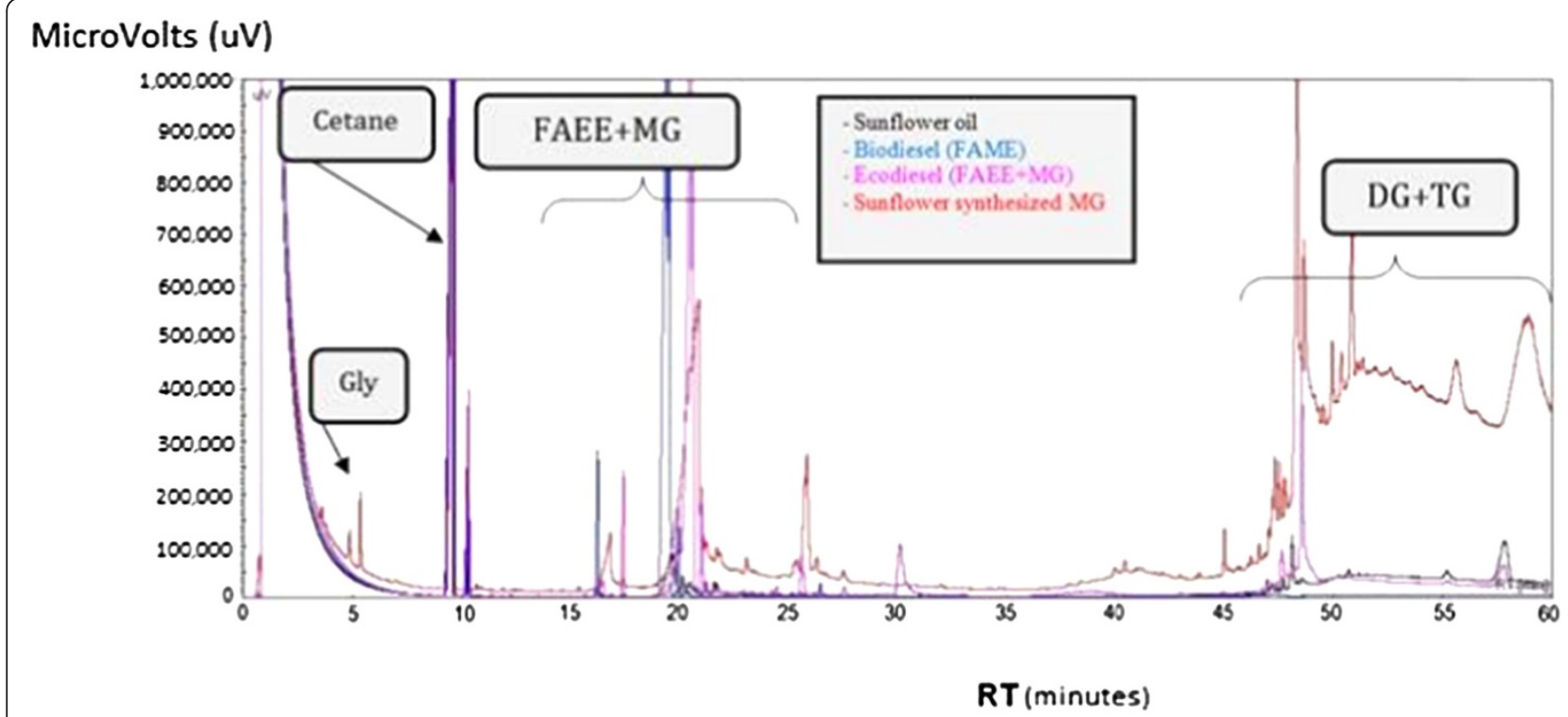

\begin{tabular}{|c|c|}
\hline Retention Time (RT/min) & Peak \\
\hline $\mathbf{0 - 7}$ & Solvent (ethanol + dichloromethane 50:50) \\
\hline $\mathbf{5}$ & Glycerol \\
\hline $\mathbf{9 - 1 0}$ & Internal Standard (n-hexadecane/ Cetane) \\
\hline $\mathbf{1 6}$ & Palmitic FAME (16:0) \\
\hline $\mathbf{1 7}$ & Palmitic MG (16:0) \\
\hline $\mathbf{1 8}$ & Palmitic FAEE (16:0) \\
\hline $\mathbf{1 9}$ & Estearic (18:0), Linoleic (18:2), Oleic (18:1) FAME \\
\hline $\mathbf{2 0}$ & Estearic (18:0), Linoleic (18:2), Oleic (18:1) FAEE \\
& Estearic (18:0), Linoleic (18:2) MG \\
\hline $\mathbf{2 6}$ & Oleic (18:1) MG \\
\hline $\mathbf{4 0 - 6 0}$ & DG + TG \\
\hline
\end{tabular}

Figure 2 Superimposed chromatograms of sunflower oil, FAME, FAEE, and MG.

Since the retention times of different derivatives of fatty acids are considered very closely related to the chemicalphysical properties of these compounds, the great similarity of RT values obtained is a clear demonstration of the similarity among the rheological properties of the different MGs with their corresponding FAMEs or FAEEs, which are crucial to allow its use as fuel able to substitute for petroleum products. Consequently, conversion is a reaction parameter where all molecules (FAEE, MG, and DG) obtained in the ethanolysis of TG are included (as \%); it will be considered as a very different parameter, with respect to selectivity, where FAEEs and MGs are only included (as \%), all of them having RT values lower than 26 min. These molecules exhibit RT values similar to hydrocarbons present in conventional diesel, so that they all could exhibit similar physicochemical and rheological properties. However, a high conversion, even 100\%, could contain a high proportion of DG molecules, with high molecular weight and high viscosity values. Consequently, a very high selectivity, indicating a very high percentage of FAEEs and MGs, could promote a viscosity value close to the petroleum diesel, so that the highest conversion value is not enough a guaranty of lower viscosity values. Thus, both parameters will be provided as GC analysis results of reaction products.

Taking into account that retention times of a complex mixture of hydrocarbons constituting fossil diesel fuel are ranging from 1 to $25 \mathrm{~min}$, it is used as a reference value for different biofuels (FAME, FAEE, MG) as selectivity value, all those FAEs that present RT values coincident with the hydrocarbons constituting diesel, or those with RT lower than $25 \mathrm{~min}$, as it is expected that they also present similar physicochemical and rheological properties to the conventional diesel. 


\section{Analysis of variance and optimization of the reaction parameters by RSM}

The analysis of variance methods has become very attractive in reaction parameter optimization and in the evaluation of the effects of the parameters in the TG transesterification reaction $[9,15,27]$ due to their effectiveness in the analysis of variables. Thus, results obtained operating under the 36 runs - each one with different experimental conditions, selected by the multifactorial design of experiments with three factors, developed by the software Stat Graphics version XV.I., where two of them are developed at three levels and the other at two levels, indicated in Table 1 - are shown in Table 2 .

The quantity of supported lipase (N435) in all these experiments was fixed to $0.5 \mathrm{~g}$. All experiments were duplicated in order to avoid experimental errors. Data was fitted to a quadratic polynomial model using the software. The quadratic polynomial model was highly significant and sufficient to explain the relationship between conversion/selectivity/kinematic viscosity and important experimental variables. Thus, the results of factorial design suggested that the major factors affecting the transesterification, for the production of biofuels integrating glycerol as monoacylglycerols, were temperature and oil/ethanol ratio $(v / v)$.

The values of correlation coefficients, $R^{2}$, were 0.816 for conversion, 0.914 for selectivity, and 0.937 for kinematic viscosity, respectively, which imply a good fit between models and experimental data in Pareto graphics, with respect to conversion, selectivity, and viscosity, as indicated in Figure 3a. The adjusted correlation coefficients $R^{2}$ were $0.762,0.889$, and 0.918 for conversion, selectivity, and kinematic viscosity, respectively. Obtained results pointed out that the temperature and oil/ethanol $(v / v)$ ratios were also important parameters influencing the conversion and viscosity in the systems $(p<0.05)$.

The software also allows to obtain equations (Equations 1, 2 , and 3), remarkably simpler as compared to initial ones after the elimination of non-influent parameters in the model for conversion, selectivity, and kinematic viscosity. These equations describe the model created and give solutions for the dependent variable based on the independent variable combinations, selecting the most significant in the response. Thus, taking into account that $R$ is the oil/ethanol

Table 1 Process parameters in factorial design: coded and actual values

\begin{tabular}{lcccc}
\hline Variables & Unit & \multicolumn{3}{c}{ Levels } \\
\cline { 3 - 5 } & & $\mathbf{- 1}$ & $\mathbf{0}$ & $\mathbf{1}$ \\
\hline Temperature & ${ }^{\circ} \mathrm{C}$ & 20 & 30 & 40 \\
Oil/ethanol ratio $(\mathrm{V} / \mathrm{v})$ & $\mathrm{ml} / \mathrm{ml}$ & $12 / 1,75$ & - & $12 / 3.5$ \\
Alkaline environment & $\mathrm{\mu l}(\mathrm{NaOH} \mathrm{10} \mathrm{N)}$ & $8(12.5)$ & $10(5)$ & $12(50)$ \\
\hline
\end{tabular}

ratio $(v / v)$, alkaline environment is obtained by the addition of different microliters of $\mathrm{NaOH} 10 \mathrm{~N}$, and $T$ is the reaction temperature,

$$
\begin{aligned}
{[\text { Conversion }(\%)=} & 93.57+5.06 \times T+7.82 \\
& \times R-6.42 \times T^{2}-6.53 \times T \\
& \times R-3.25 \times R \times \mathrm{pH}]
\end{aligned}
$$

$$
\begin{aligned}
\text { Selectivity }(\%)= & 35.97+6.26 \times T-2.25 \times \mathrm{pH} \\
& +4.50 \times R+6.93 \times T \times \mathrm{pH} \\
& -12.22 \times T \times R+6.13 \times \mathrm{pH}^{2} \\
& -6.61 \times \mathrm{pH} \times R]
\end{aligned}
$$

$$
\begin{aligned}
{[\operatorname{Viscosity}(\mathrm{cSt})=} & 17.27+1.65 \times T-2.32 \times R \\
& +0.97 \times T^{2}+1.95 \times T \times R \\
& +1.20 \times R \times \mathrm{pH}] .
\end{aligned}
$$

The surface plots in Figure $3 \mathrm{~b}$, described by the regression model, were drawn to display the effects of the independent variables on conversion, selectivity, and kinematic viscosity. Here, the influence of the different variables in the conversion of the systems can be clearly seen. This model showed that the optimum values for the parameters to maximize transesterification yield (conversion, selectivity, kinematic viscosity) were intermediate temperatures $\left(30^{\circ} \mathrm{C}\right)$, maximum amount of aqueous $\mathrm{NaOH} 10 \mathrm{~N}$ added $(50 \mu \mathrm{l})$, and the maximum oil/ethanol $(v / v)$ ratio $=6: 1$ studied. Conversions up to $100 \%$, selectivities around $70 \%$, and values of kinematic viscosity about 10 to $15 \mathrm{~mm}^{2} \mathrm{~s}^{-1}$ could be achieved under these conditions, which in theory will render feasible the utilization of the obtained biofuel in blends with diesel. For example, by the addition of only $35 \%$ of diesel fossil, to this biofuel, a viscosity reduction at $4.8 \mathrm{~mm}^{2} \mathrm{~s}^{-1}$, a value within the acceptance limits of the EN 14214, is obtained.

\section{Effect of the amount of lipase}

The effect of the amount of lipase in the reaction media is very important to select the correct reaction conditions. This parameter was evaluated in order to choose the necessary amount of lipase that maximizes yield without mass transfer limitations. Previous optimized values obtained from RSM (12 ml oil/3.5 ml EtOH, $30^{\circ} \mathrm{C}, 12.5 \mu \mathrm{l}$ $\mathrm{NaOH} 10 \mathrm{~N}$, stirring speed higher than $300 \mathrm{rpm}$ for $2 \mathrm{~h}$ ) were chosen.

We can see in Figure 4 how the reaction yield and viscosity were improved, so better values could be obtained using more quantities of biocatalyst, but larger amounts of enzymes will have a detrimental effect on the economics of the process. 
Table 2 Experiment matrix of factorial design and the response obtained for conversion, selectivity, and viscosity

\begin{tabular}{|c|c|c|c|c|c|c|}
\hline \multirow[t]{2}{*}{ Run } & \multicolumn{6}{|c|}{ Parameters } \\
\hline & Temperature & Oil/ethanol ratio & $\mathrm{pH}$ & Conversion (\%) & Selectivity (\%) & Kinematic viscosity $\left(\mathrm{mm}^{2} \mathrm{~s}^{-1}\right)$ \\
\hline 1 & 1 & -1 & 0 & 81.4 & 45.99 & 20.3 \\
\hline 2 & 1 & -1 & -1 & 84.6 & 46.1 & 21.3 \\
\hline 3 & 0 & -1 & -1 & 78.6 & 29.2 & 21.0 \\
\hline 4 & -1 & -1 & 0 & 59.1 & 11.7 & 20.8 \\
\hline 5 & -1 & 1 & 1 & 100 & 40.4 & 13.3 \\
\hline 6 & 1 & 1 & 1 & 100 & 39.6 & 22.3 \\
\hline 7 & -1 & -1 & -1 & 63.6 & 23.3 & 22.1 \\
\hline 8 & 0 & -1 & 1 & 89.5 & 34.1 & 19.0 \\
\hline 9 & 0 & 1 & 0 & 95.7 & 31.4 & 15.2 \\
\hline 10 & 0 & -1 & 0 & 100 & 44.2 & 20.1 \\
\hline 11 & 0 & 1 & 1 & 95.2 & 37.5 & 15.7 \\
\hline 12 & 1 & -1 & 1 & 100 & 72.5 & 18.6 \\
\hline 13 & 1 & 1 & -1 & 100 & 46.6 & 18.2 \\
\hline 14 & 1 & 1 & 0 & 86.1 & 36.1 & 19.8 \\
\hline 15 & -1 & 1 & 0 & 94.9 & 46.8 & 13.4 \\
\hline 16 & -1 & 1 & -1 & 100 & 70.9 & 10.8 \\
\hline 17 & 0 & 1 & -1 & 100 & 52.6 & 12.5 \\
\hline 18 & -1 & -1 & 1 & 77.5 & 17.8 & 20.2 \\
\hline \multicolumn{7}{|c|}{ Repeated experiments } \\
\hline 19 & 0 & -1 & 0 & 100 & 43.4 & 22.5 \\
\hline 20 & -1 & 1 & 1 & 100 & 39.7 & 13.2 \\
\hline 21 & -1 & -1 & -1 & 64.4 & 22.6 & 20.1 \\
\hline 22 & -1 & 1 & 0 & 95.8 & 46.1 & 13.4 \\
\hline 23 & 1 & 1 & -1 & 100 & 47.5 & 16.2 \\
\hline 24 & 0 & 1 & -1 & 100 & 51.9 & 14.5 \\
\hline 25 & -1 & 1 & -1 & 100 & 69.6 & 10.9 \\
\hline 26 & 0 & 1 & 0 & 96.5 & 36.5 & 14.6 \\
\hline 27 & 1 & 1 & 1 & 100 & 38.8 & 22.2 \\
\hline 28 & 0 & -1 & -1 & 80.1 & 28.6 & 19.0 \\
\hline 29 & 1 & -1 & 1 & 100 & 71.4 & 18.5 \\
\hline 30 & -1 & -1 & 0 & 60.2 & 11.0 & 20.3 \\
\hline 31 & 1 & -1 & 0 & 82.2 & 45.2 & 20.3 \\
\hline 32 & 1 & 1 & 0 & 86.9 & 33.4 & 19.5 \\
\hline 33 & 0 & -1 & 1 & 90.3 & 33.4 & 18.1 \\
\hline 34 & 0 & 1 & 1 & 97.0 & 36.8 & 15.1 \\
\hline 35 & 1 & -1 & -1 & 85.4 & 43.4 & 21.6 \\
\hline 36 & -1 & -1 & 1 & 69.7 & 16.3 & 20.6 \\
\hline
\end{tabular}

\section{Study of enzyme activity in successive reactions}

Since we have been doing these successive reactions, the reaction conditions have been changed such that the procedure enables the study according to OVAT ('variable at one time') methodology in which initial conditions are set and variables to study have been changed one by one. This method does not provide information on the combined effect of various reaction parameters, but it is useful to determine the influence of isolated variables. Because our research group had previous information about other lipase enzymes [12-15] and what were the most important reaction variables, it was decided to use this experimental 


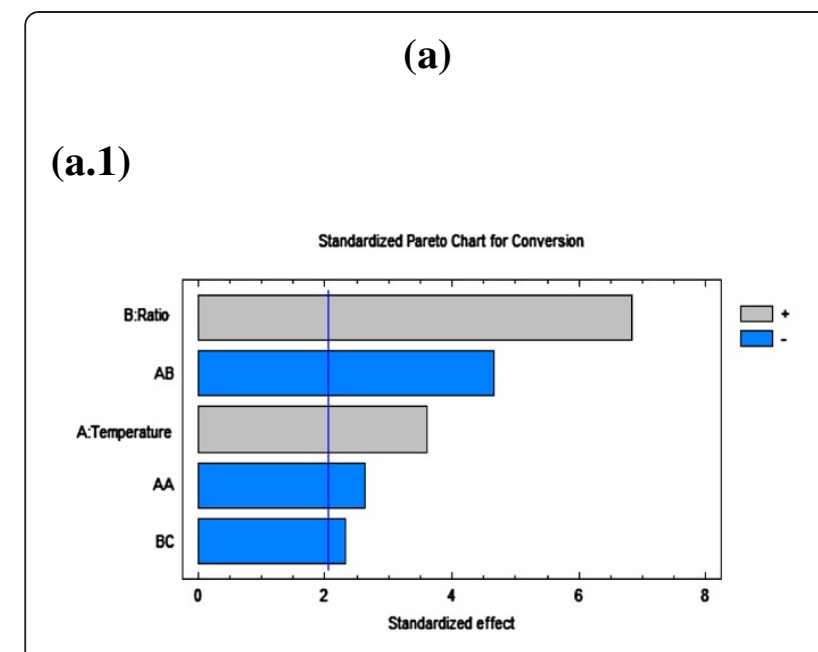

(b.1)

\section{(a.2)}

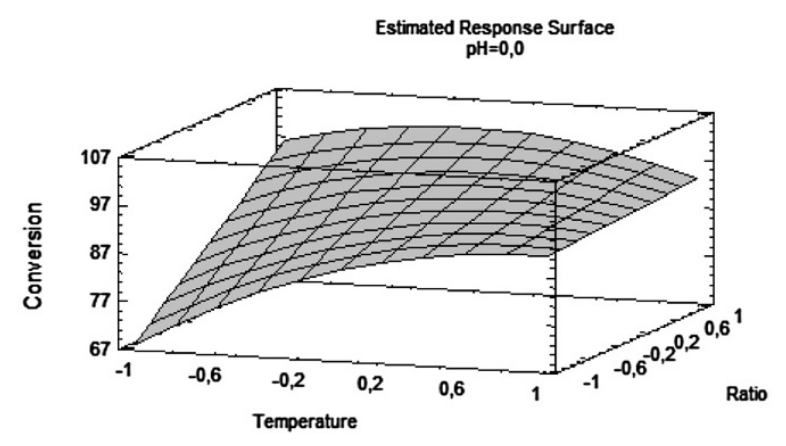

(b.2)
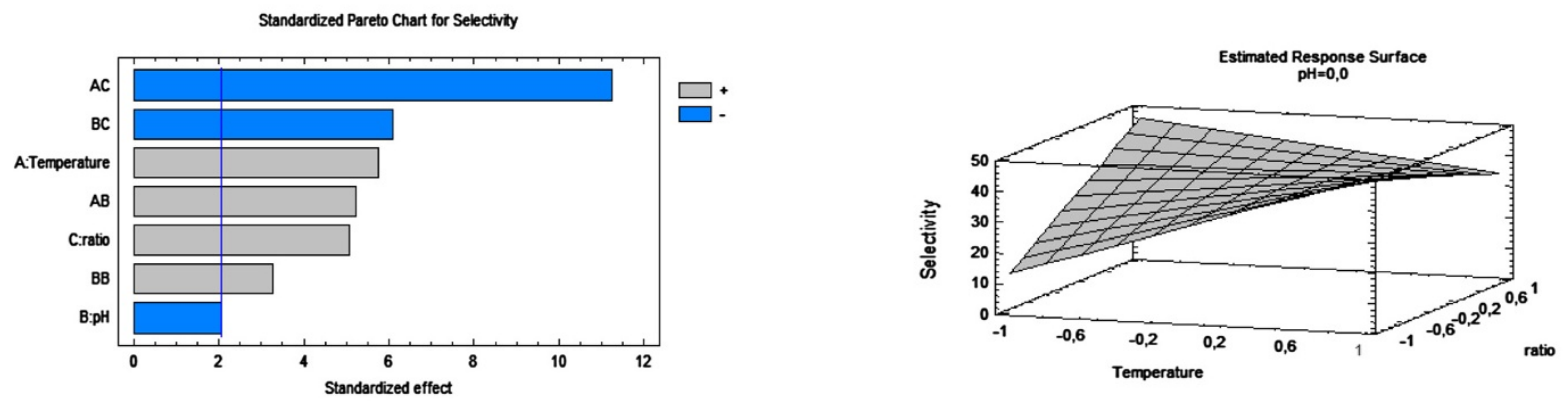

(a.3)

(b.3)
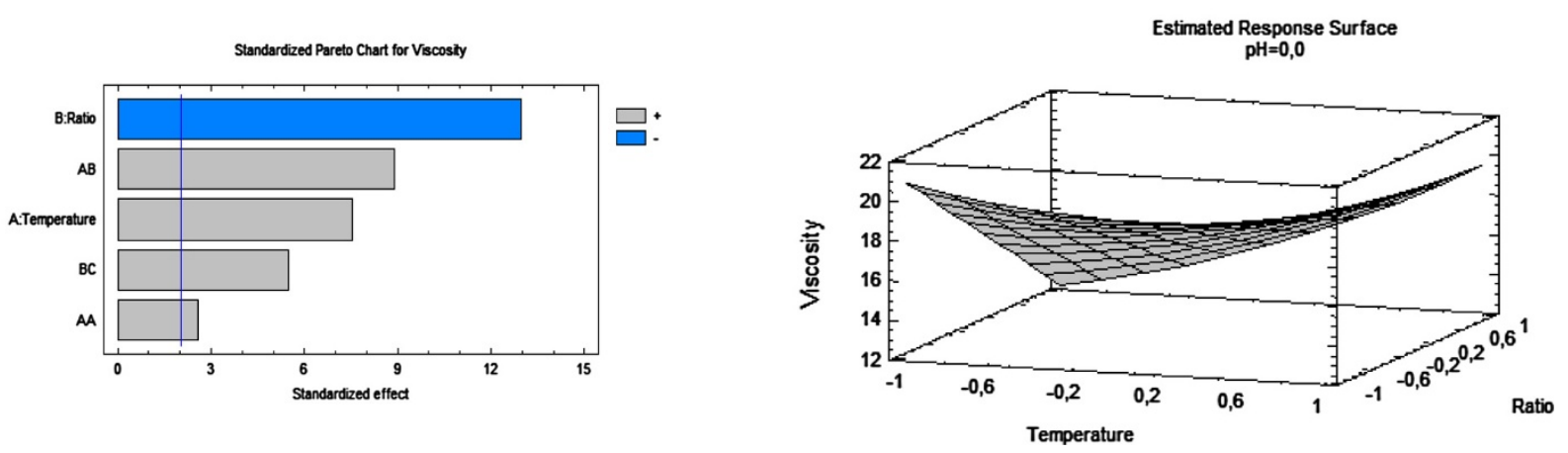

Figure 3 Pareto graphics and response surface plots. (a) Pareto graphics: conversion (a.1), selectivity (a.2), and viscosity (a.3). (b) Response surface plot of more influential parameters: conversion (b.1), selectivity (b.2), and viscosity (b.3).

methodology in order to evaluate in more detail the influence of those variables in the selected intervals for each study.

In this way, reaction tests of N435 lipase systems have been carried out under the optimum conditions (alkaline environments, temperatures, and relative oil/ethanol ratio) previously determined by the RSM studies. These experimental conditions were similar to those previously obtained with $T$. lanuginosus, Lipopan 50 BG Lipopan [15]. In this respect, Table 3 shows a collection of the achieved 


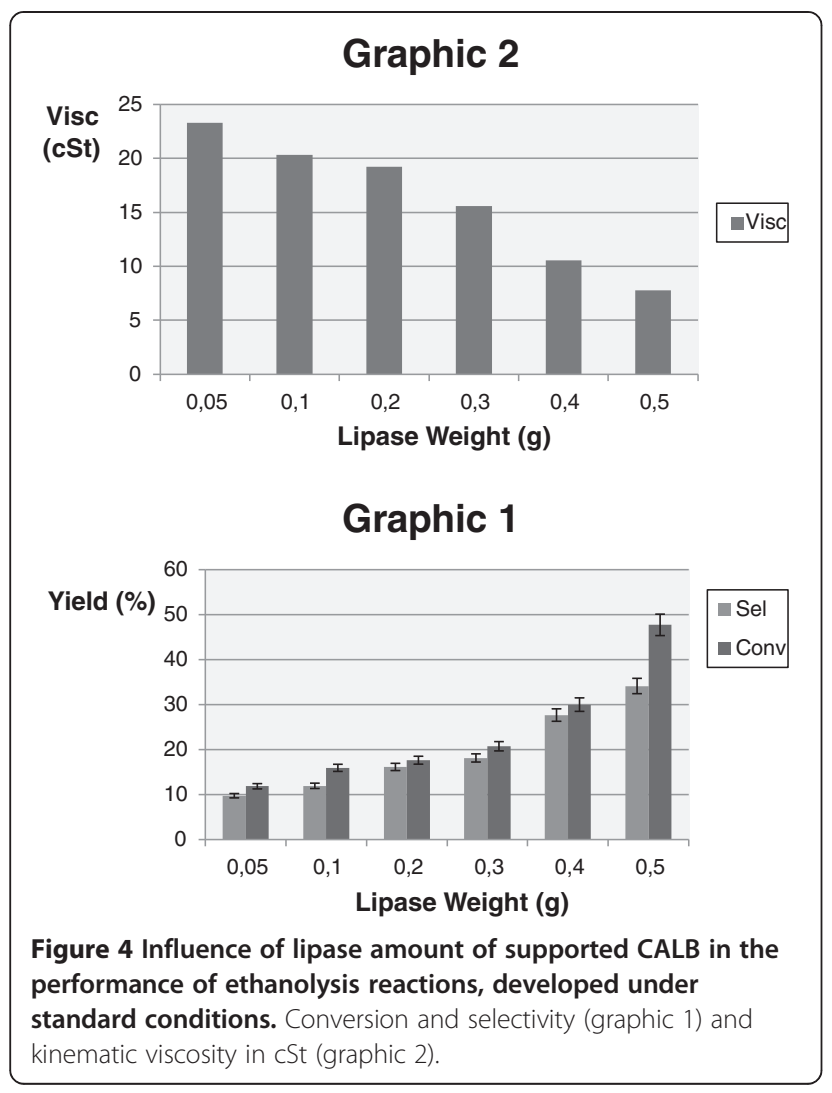

Table 3 Achieved results in the transesterification reaction with biocatalyst

\begin{tabular}{lcccccccc}
\hline Run number & NaOH amount & Temperature & EtOH/oil & Viscosity & Selectivity & Conversion & TOF & Enzyme activity \\
\hline 1 & 25 & 30 & $3.5 / 12(6: 1)$ & 10.5 & 34.9 & 47.7 & 79.5 & 0.24 \\
2 & 25 & 30 & $3.5 / 12(6: 1)$ & 13.7 & 23.6 & 32.9 & 54.83 & 0.35 \\
3 & 25 & 30 & $3.5 / 12(6: 1)$ & 12.8 & 24.1 & 31.8 & 53.00 & 0.36 \\
4 & 25 & 30 & $3.5 / 12(6: 1)$ & 13.3 & 25.6 & 33.9 & 56.50 & 0.33 \\
5 & 25 & 30 & $3.5 / 12(6: 1)$ & 12.8 & 29.1 & 35.6 & 59.33 & 0.32 \\
6 & 12.5 & 35 & $3.5 / 12(6: 1)$ & 13.8 & 14.5 & 20.1 & 33.50 & 0.57 \\
7 & 12.5 & 30 & $3.5 / 12(6: 1)$ & 12.3 & 45.4 & 57.9 & 96.50 & 0.20 \\
8 & 12.5 & 25 & $3.5 / 12(6: 1)$ & 14.6 & 21.4 & 25.8 & 43.00 & 0.44 \\
9 & 12.5 & 40 & $3.5 / 12(6: 1)$ & 20.9 & 7.6 & 4.0 & 6.67 & 2.85 \\
10 & 12.5 & 30 & $1.75 / 12(3: 1)$ & 18,8 & 17,9 & 27.4 & 45.67 & 0.42 \\
11 & 12.5 & 20 & $3.5 / 12(6: 1)$ & 18.1 & 17.5 & 22.4 & 37.33 & 0.51 \\
12 & 12.5 & 30 & $2.3 / 12(4: 1)$ & 20.0 & 17.6 & 21.4 & 35.67 & 0.53 \\
13 & 12.5 & 30 & $2.9 / 12(5: 1)$ & 10.6 & 34.1 & 47.7 & 79.50 & 0.24 \\
15 & 12.5 & 30 & $3.5 / 12(6: 1)$ & 10.4 & 39.1 & 51.9 & 86.50 & 0.22 \\
16 & 12.5 & 30 & $4.1 / 12(7: 1)$ & 17.9 & 14.1 & 16.8 & 28.00 & 0.68 \\
\hline
\end{tabular}

Viscosity (cSt), conversion (\%), selectivity (\%), turnover frequencies (TOF in $\mu \mathrm{mol} \mathrm{min}^{-1} \mathrm{~g} \mathrm{cat}^{-1}$ ), and enzyme activities (U/mg lipase) of the obtained biodiesel by using the same biocatalyst $(0.5 \mathrm{~g}$ of $\mathrm{N} 435)$ in successive reactions under the evaluated different experimental conditions: temperature $\left({ }^{\circ} \mathrm{C}\right)$, $\mathrm{NaOH}$ amount ( $\mu$ l of $\mathrm{NaOH} 10 \mathrm{~N}$ solution), and EtOH/oil ratio $(\mathrm{ml} / \mathrm{ml}$ or $\mathrm{mol} / \mathrm{mol})$. results in the transesterification reaction with this biocatalyst. Thus, in addition to obtain specific information about the influence of certain parameters (alkaline environment, temperature, etc.) on the behavior of the N435, its ability to be reused could be checked.

In this sense, from the conversion, given that we start from $0.01 \mathrm{~mol}$ of TG, with $2 \mathrm{~h}$ as reaction time and $0.5 \mathrm{~g}$ of catalyst system (lipase CALB immobilized on acrylic capacity: turnover frequency (TOF number) expressed in micromoles of TG transformed per minute and per gram of catalyst (supported lipase). In order to be able to obtain the enzyme activity of the immobilized CALB, some research experiments with a purified powdered commercial lipase B from C. antarctica, recombinant from A. oryzae, have been conducted. Thus, operating under identical experimental conditions with those used in experiments carried out with $\mathrm{N} 435$, but using only $0.01 \mathrm{~g}$ of purified CALB in free form, a conversion of $50.6 \%$ was obtained. Excluding the possible influence of support effects in the lipase activity, and taking into account that $0.5 \mathrm{~g}$ of CALB immobilized enzyme produced a $47.7 \%$ conversion, it can be inferred that $\mathrm{N} 435$ has a catalytic activity corresponding to the $1.9 \%$ of the obtained catalytic activity by the free CALB.

Therefore, to obtain a reference value, and assuming that the activity of the immobilized enzyme is similar to that of the free enzyme, it can be considered that the N435 may contain about 1.9 wt\% of immobilized enzyme. In any case, it works with this equivalent enzyme polymer), we can calculate the transformation enzymatic 
activity. From this parameter, a reference value of the catalytic activity of the immobilized enzymes, expressed in milligrams of enzyme required to convert $1 \mu \mathrm{mol}$ of TG per minute (U/mg), can also be calculated.

If we subdivide the results in Table 3 in terms of the variable that has been changed each time in the study with OVAT methodology and if we organize these results in their corresponding graphics (Figure 5), the influence of each variable on the transesterification reaction yield is clearly displayed and we reached similar conclusions to those obtained in the analysis of variance (ANOVA) study by RSM; the optimum reaction parameters for the enzymatic ethanolysis reaction with lipase N435, CALB (C. antarctica lipase B) immobilized on acrylic resin, are $30^{\circ} \mathrm{C}$ and $12.5 \mu \mathrm{l}$ of $10 \mathrm{~N} \mathrm{NaOH}$, with 1:6 oil/ethanol molar ratio.

Also, we can obtain from the data in Table 3 that N435 may be reused repeatedly. Thus, 16 reactions were (a)

(a.2)

\section{Graphic 2}

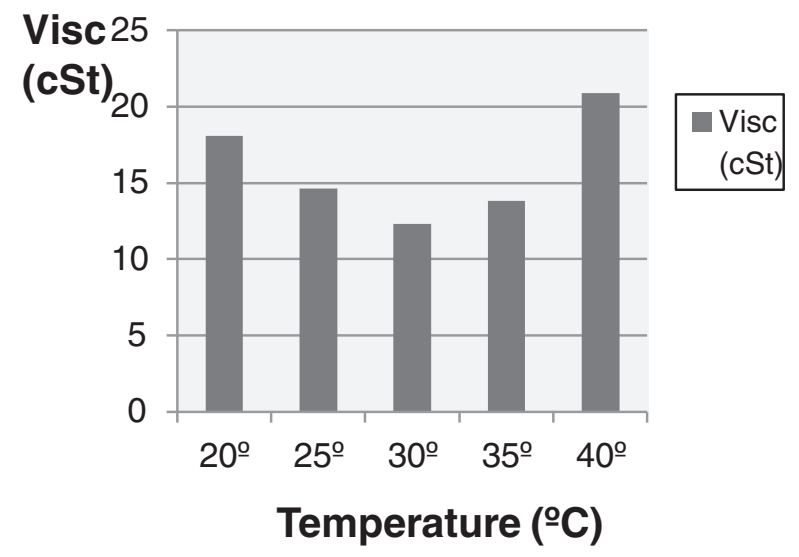

(a.1)

\section{Graphic 1}

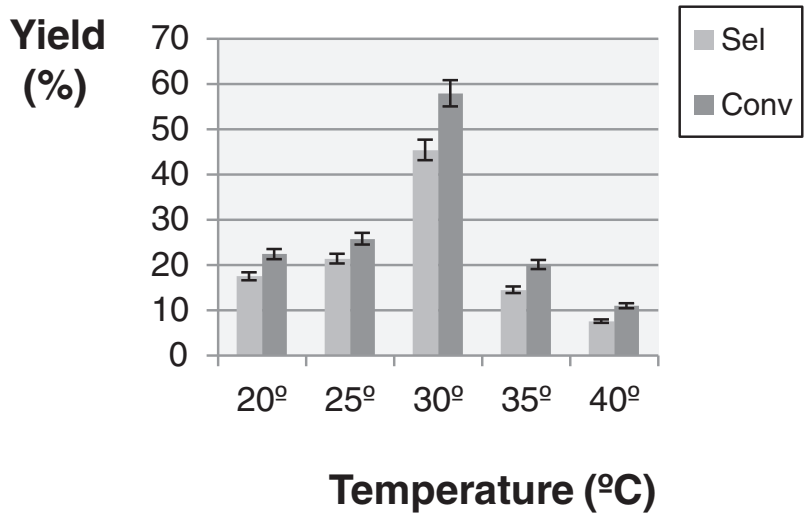

(b)

\section{(b.2)}

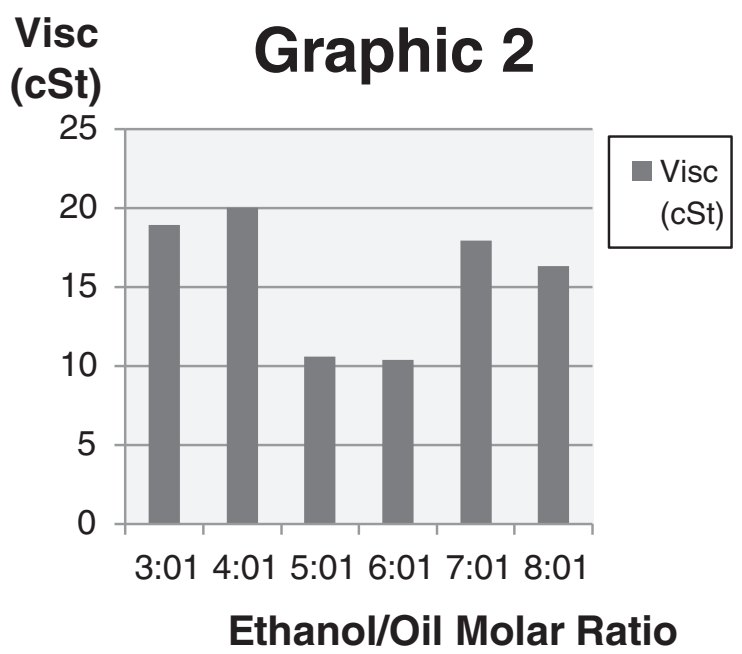

(b.1)
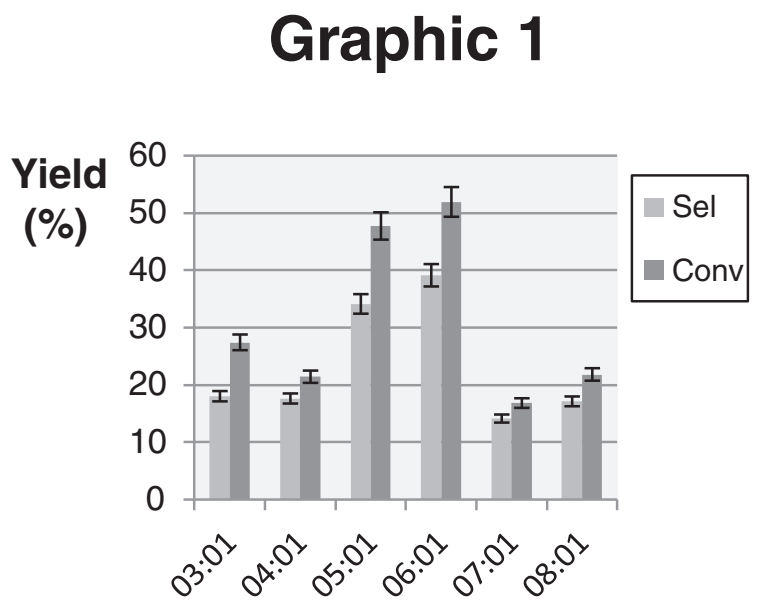

Ethanol/Oil Molar Ratio

Figure 5 Reaction temperature and oil/ethanol molar ratio. Influence of the (a) reaction temperature and (b) oil/ethanol molar ratio in the enzymatic ethanolysis reaction performance of supported CALB developed under standard conditions. Conversion and selectivity (graphic 1) and viscosity in CSt (graphic 2). 
developed successively without an appreciable loss in catalytic activity in the ethanolysis reaction of sunflower oil, operating under different experimental conditions. However, an important drawback is associated to its acrylic polymeric character. Thus, to recover the immobilized lipase on macroporous resin, after each successive reaction, it is necessary to carry out the centrifugation of reaction products.

Finally, this research, developed in order to improve a new methodology to integrate the glycerol as different monoacylglycerol molecules, is in connection with precedent researches performed to determine the optimal experimental conditions of the selective ethanolysis reaction. In this respect, the results here obtained resemble those described with the commercial PPL lipases [12-14] and with a low-cost purified lipase, [15] from T. lanuginosus, Lipopan 50 BG (Novozymes A/S), widely used in the bakery industry as an emulsifier [24]. In this respect, the possibility of application of commercial immobilized lipases in this process is now explored to exploit the opportunity of its reuse, thus lowering its operational cost and consequently increasing the economic potential of their industrial application. Thus, in this study, the behavior of a commercial supported lipase, Novozym 435, is determined because this may involve some technological advantages in its development, so that this study has the aim to prove its viability, its yield, and its possibility of reuse, what will mean an important advance in its biotechnological applications in the biofuel enzymatic production [5].

Currently, results obtained in this study indicate that this commercial supported lipase is specially efficient in obtaining 1,3-selective ethanolysis processes, where glycerol is maintained as MG in the biofuel mixture, with the different obtained FAEEs and together to the excess of unreacted ethanol. In this way, a new kind of biodiesel currently named Ecodiesel is achieved, constituted by a mixture of monoacylglycerols and FAEEs mainly $(1 / 2$ nominally), which can be used in different blends with diesel fuel, without anymore separation or purification process. This new biofuel can be obtained with the help of N435 at very short reaction times (1 to $2 \mathrm{~h}$ ) and under soft reaction conditions. Besides, not only a higher atomic yield is achieved, with respect to the conventional biodiesel reaction (because no glycerol by-product is generated), but also a purification step of residual glycerol is not necessary, so it can be used directly after its production.

Despite the good results obtained in the transesterification reaction of sunflower oil with ethanol to produce FAEE and MG, unfortunately, the main drawback of this commercial biocatalyst is the low stability of the organic polymeric little spheres which constitute the catalytic powder that easily disintegrates in the first ethanolysis reaction and becomes a gelatinous material which is very uncomfortable to work in the successive reuses, so that centrifugation of reaction products is necessary for catalyst recovery to avoid important losses of catalyst. This additional centrifugation step may constitute a major drawback for the application of the process on an industrial scale.

\section{Experimental \\ Ethanolysis reactions}

These reactions were performed according to the experimental procedure previously described [12-15] to determine the optimal conditions for obtaining the selective ethanolysis reaction, such as alkaline environment, amount of lipase, the oil/ethanol molar ratio $(v / v)$, and temperature. Thus, enzymatic assays are carried out with $9.4 \mathrm{~g}(12 \mathrm{ml}$, $0.01 \mathrm{~mol}$ ) of commercial sunflower oil at controlled temperatures $\left(20^{\circ} \mathrm{C}\right.$ to $\left.40^{\circ} \mathrm{C}\right)$ in a $25-\mathrm{ml}$ round bottom flask. Reaction mixtures were stirred with a conventional magnetic stirrer at a stirring speed higher than $300 \mathrm{rpm}$ to avoid mass transfer limitations, along a reaction time of $2 \mathrm{~h}$. Variable oil/alcohol volume ratios at different alkaline environments and different quantities of lipase are studied. The different oil/ethanol ratios $(v / v)$ are obtained by introducing absolute ethanol volumes in the range of 1.75 to $3.5 \mathrm{ml}$, and the influence of different amounts of lipase is studied in the range of 0.05 to $0.5 \mathrm{~g}$. The influence of alkaline environment values was achieved by adding different volumes $(12.5$ to $50 \mu \mathrm{l})$ of $10 \mathrm{~N} \mathrm{NaOH}$ aqueous solution. In this regard, a blank reaction in the presence of the highest quantity of solution of $\mathrm{NaOH}$ was performed to rule out a potential contribution from the homogeneous $\mathrm{NaOH}$ catalyzed reaction. Less than $10 \%$ conversion of the starting material was obtained, so that a homogenous base catalysis contribution can be considered as negligible under the investigated conditions.

In this respect, the $\mathrm{NaOH}$ solution, to operate as a transesterification catalyst, needs usually to be used under higher temperatures and under higher catalyst concentrations ( 1 to $2 \mathrm{wt} \%$ ), enough to generate sodium methoxide or ethoxide, the true catalyst of the homogeneous transesterification reaction. Thus, the use of a very small concentration of $\mathrm{NaOH}$ works as a promoter of the process, through its effect on the lipase biocatalytic activity. Accordingly, $\mathrm{NaOH}$ ions are responsible for the $\mathrm{pH}$ environment that affects the enzyme yield, because depending on the $\mathrm{pH}$, the enzymatic protein offers different structures, more or less effective in the biocatalytic action.

All variables were studied and optimized according to a factorial experimental design and a response surface methodology.

\section{Analytical method}

Reaction products were monitored by capillary column gas chromatography, using a Varian 430-GC gas chromatograph 
(Varian Inc., Palo Alto, CA, USA), connected to a HT5 capillary column $(25 \mathrm{~m} \times 0.32 \mathrm{~mm} \mathrm{ID} \times 0.1 \mu \mathrm{m}, \mathrm{SGE}$, Supelco) with a flame ionization detector (FID) at $450^{\circ} \mathrm{C}$ and splitless injection at $350^{\circ} \mathrm{C}$. Helium is used as carrier gas with a flow of $1.5 \mathrm{ml} / \mathrm{min}$. A heating ramp from $90^{\circ} \mathrm{C}$ to $200^{\circ} \mathrm{C}$ at a rate of $7^{\circ} \mathrm{C} / \mathrm{min}$ has been applied, followed by another ramp from $200^{\circ} \mathrm{C}$ to $360^{\circ} \mathrm{C}$ at a rate of $15^{\circ} \mathrm{C} /$ min, maintaining the temperature of the oven at $360^{\circ} \mathrm{C}$ for 10 min using as internal standard $n$-hexadecane (cetane) to quantify the content of ethyl esters and the different glycerides (mono-, di-, and triglycerides) with the help of several commercial standard fatty acid esters. This method allows us to make a complete analysis of the sample in a single injection and in a time not longer than $60 \mathrm{~min}$, which simplifies the process and increases the speed of analysis [12-15].

Considering that sunflower oil is constituted by a mixture of fatty acids in variable proportion (mainly linoleic, oleic, palmitic, and stearic acids), the results obtained are expressed as the relative amounts of the corresponding ethyl esters (FAEE, fatty acid ethyl esters), monoglycerides (MG), and diglycerides (DG) that are integrated in the chromatogram. The amount of triglycerides (TG) which has not reacted is calculated from the difference to the internal standard (cetane). Thus, the conversion includes the total amount of triglyceride transformed $(\mathrm{FAEE}+\mathrm{MG}+\mathrm{DG})$ in the ethanolysis process, and selectivity makes reference to the relative amount of FAEE + MG obtained. The latter are the ones having retention times close to the cetane standard, which is the reference hydrocarbon for diesel fuel.

\section{Viscosity measurements}

The transesterification reactions of oils and fats are basically carried out to obtain an important reduction in the viscosity of these materials, as they share similar values in all of other chemical-physical significant parameters with the fossil diesel except the viscosity. In this respect, most oils exhibit viscosities in the range of 30 to $45 \mathrm{~mm}^{2} / \mathrm{s}$ cSt values, while the fossil diesel is in the range of 2.5 to $6 \mathrm{cSt}$ values. Thus, due to the importance of viscosity for the correct running of diesel engines, this parameter becomes a critical factor to change the chemical-physical properties of vegetable oils before their use as biofuel. The transesterification process of oils and fats is actually developed in order to obtain a noticeable lowering of viscosity in oils to employ the resulting product as biofuel in current existing diesel engines. Thus, accurate viscosity measurements are critical to assess the quality of biofuels produced, since unsuitable viscosity values can decisively affect the correct working conditions of the diesel engine. Therefore, the characterization of this parameter is essential to evaluate the result obtained in the process of ethanolysis.
Viscosities were determined in a capillary viscometer Oswald Proton Cannon-Fenske Routine Viscometer 33200, size 150. This is based on determining the time needed for a given volume of fluid passing between two points marked on the instrument. The kinematic viscosity is given by the ratio between the dynamic viscosity ( $h$, in Poise, g/cm s) and the density $\left(r\right.$, in $\left.\mathrm{g} / \mathrm{cm}^{3}\right) v=h / r$ (in $\mathrm{cm}^{2} / \mathrm{s}$ or centistokes $\left.(\mathrm{cSt}), \mathrm{mm}^{2} / \mathrm{s}\right)$. Samples, previously centrifuged at $3,500 \mathrm{rpm}$ for $10 \mathrm{~min}$ and filtered at $50^{\circ} \mathrm{C}$, are immersed in a thermostatic bath at $40^{\circ} \mathrm{C}$ for $15 \mathrm{~min}$, making sure that the temperature is stable. Then, samples are introduced into the viscometer and this, in turn, in the water bath, making sure that it is rigorously positioned vertically, with the bottom end at a minimum distance of $2 \mathrm{~cm}$ from the floor of the bath [12-15].

\section{Experimental design}

The effect of process parameters in the enzymatic transesterification reaction to obtain the optimum conditions for the viscosity, selectivity, and conversion was studied using a multifactorial design of experiments with three factors run by the software Stat Graphics version XV.I. Two of them are developed at three levels and the last one at two levels, so that it gives 36 runs. The experiments were performed in random order. The experimental parameters selected for this study were reaction temperature, oil/ethanol ratio $(v / v)$, and different alkaline environments obtained by the addition of variable volumes (in $\mu \mathrm{l}$ ) of $\mathrm{NaOH} 10 \mathrm{~N}$. Table 1 shows the coded and actual values of the process parameters used in the design matrix.

\section{Statistical analysis}

The experimental data obtained from experimental design were analyzed by response surface methodology (RSM) [9,15,27]. A mathematical model, following a second-order polynomial equation, was developed to describe the relationships between the predicted response variable (viscosity, conversion, and selectivity) and the independent variables of reaction conditions, as shown in the Equation 4, where $Y$ is the predicted response variable; $\beta_{0}, \beta_{i}, \beta_{i i}$, and $\beta_{i j}$ are the intercept, linear, quadratic, and interaction constant coefficients of the model, respectively; and $X_{i}$ and $X_{j}(i=1,3 ; j=1,3 ; i \neq j)$ represent the coded independent variables.

$$
Y=\beta_{0}+\sum_{i=1}^{3} \beta_{0} x_{i}+\sum_{i=1}^{3} \beta_{i i} x_{i}^{2}+\sum \sum_{i<j=1}^{3} \beta_{i j} x_{i} x_{j}
$$

Response surface plots were developed using the fitted quadratic polynomial equation obtained from regression analysis, holding one of the independent variables at constant values corresponding to the stationary point and changing the order of two variables. The quality of 
the fit of the polynomial model equation was evaluated by the coefficient of determination $R^{2}$, and its regression coefficient significance was checked with $F$-test. Confirmatory experiments were carried out in order to validate the model, using combinations of independent variables which were not part of the original experimental design but within the experimental region.

\section{Conclusions}

Novozym 435 lipase was evaluated in the 1,3-selective ethanolysis of sunflower oil to integrate the glycerol as monoacylglycerol molecules. On the basis of RSM analysis, the optimum conditions for synthesis were 1:6 molar oil/EtOH ratio, $30^{\circ} \mathrm{C}$, and $12.5 \mu \mathrm{l} \mathrm{NaOH} 10 \mathrm{~N}$ aqueous solutions, with stirring speed higher than $300 \mathrm{rpm}$ for $2 \mathrm{~h}$ and $0.5 \mathrm{~g}$ of biocatalyst. Accordingly, its ability to be repeatedly reused could open a new way for the production of alternative biodiesel using an enzymatic approach, which is technically feasible and economically viable. The main drawback is the permanent need for centrifugation to recover the biocatalyst for the next reuse.

\footnotetext{
Abbreviations

ANOVA: analysis of variance; CALB: Candida antarctica lipase B;

DG: diacylglycerol; FAE: fatty acid esters; FAEE: fatty acid ethyl esters; FAME: fatty acid methyl esters; MG: monoacylglycerol; OVAT: variable at one time; RSM: response surface methodology; TG: triacylglycerol; TOF: turnover frequency.
}

\section{Competing interests}

The authors declare that they have no competing interests.

\section{Authors' contributions}

$C L, C V, E D S, D L, J C, A P, F M B$, and $A A R$ have made substantive intellectual contributions to this study, making substantial contributions to the conception and design of it as well as to the acquisition, analysis, and interpretation of data. All of them have been also involved in the drafting and revision of the manuscript. All authors read and approved the final manuscript.

\section{Acknowledgements}

Grants from the Spanish Ministry of Economy and Competitiveness (Project ENE 2011-27017), Spanish Ministry of Education and Science (Projects CTQ2010-18126 and CTQ2011-28954-C02-02), FEDER funds and Junta de Andalucía FQM 0191, PO8-RMN-03515 and P11-TEP-7723 are gratefully acknowledged by the authors. We are also grateful to Novozymes A/S, Denmark, for the kind supply of the macroporous resin immobilized lipase from Candida antarctica (Novozym 435).

\section{Author details}

'Department of Organic Chemistry, University of Cordoba, Campus de Rabanales, Bldg. Marie Curie, 14014, Cordoba, Spain. ${ }^{2}$ Crystallographic Studies Laboratory, Andalusian Institute of Earth Sciences, CSIC, Avda. Las Palmeras, n4, 18100, Armilla, Granada, Spain. ${ }^{3}$ Department of Microbiology, University of Cordoba, Campus de Rabanales, Ed. Severo Ochoa, 14014, Cordoba, Spain. ${ }^{4}$ Seneca Green Catalyst S.A., Bldg Centauro, Technological Science Park of Cordoba, Rabanales XXI, 14014, Córdoba, Spain.

\section{Received: 22 April 2014 Accepted: 22 July 2014}

Published: 31 August 2014

\section{References}

1. Demirbas A (2009) Political, economic and environmental impacts of biofuels: a review. Appl Energy 86:108-117
2. Luque R, Herrero-Davila L, Campelo JM, Clark JH, Hidalgo JM, Luna D, Marinas JM, Romero AA (2008) Biofuels: a technological perspective. Energy Environ Sci 1:542-564

3. Oh PP, Lau HLN, Chen JH, Chong MF, Choo YM (2012) A review on conventional technologies and emerging process intensification (PI) methods for biodiesel production. Renew Sust Energy Rev 16:5131-5145

4. Saleh J, Dube MA, Tremblay AY (2011) Separation of glycerol from FAME using ceramic membranes. Fuel Process Technol 92:1305-1310

5. Calero J, Luna D, Sancho ED, Luna C, Posadillo A, Bautista FM, Romero AA, Berbel J, Verdugo C (2014) Technological challenges for the production of biodiesel in arid lands. J Arid Environ 102:127-138

6. Ganesan D, Rajendran A, Thangavelu V (2009) An overview on the recent advances in the transesterification of vegetable oils for biodiesel production using chemical and biocatalysts. Rev Environ Sci Biotech 8:367-394

7. Ilham Z, Saka S (2010) Two-step supercritical dimethyl carbonate method for biodiesel production from Jatropha curcas oil. Bioresour Technol 101:2735-2740

8. Kim SJ, Jung SM, Park YC, Park K (2007) Lipase catalyzed transesterification of soybean oil using ethyl acetate, an alternative acyl acceptor. Biotechnol Bioprocess Eng 12:441-445

9. Tan KT, Lee KT, Mohamed AR (2011) A glycerol-free process to produce biodiesel by supercritical methyl acetate technology: an optimization study via response surface methodology. Bioresour Technol 102:3990-3991

10. Casas A, Ruiz JR, Ramos MJ, Perez A (2010) Effects of triacetin on biodiesel quality. Energy Fuels 24:4481-4489

11. Verdugo C, Luque R, Luna D, Hidalgo JM, Posadillo A, Sancho ED, Rodriguez S, Ferreira-Dias S, Bautista F, Romero AA (2010) A comprehensive study of reaction parameters in the enzymatic production of novel biofuels integrating glycerol into their composition. Bioresour Technol 101:6657-6662

12. Caballero V, Bautista FM, Campelo JM, Luna D, Marinas JM, Romero AA, Hidalgo JM, Luque R, Macario A, Giordano G (2009) Sustainable preparation of a novel glycerol-free biofuel by using pig pancreatic lipase: partial 1,3regiospecific alcoholysis of sunflower oil. Process Biochem 44:334-342

13. Luna D, Posadillo A, Caballero V, Verdugo C, Bautista FM, Romero AA, Sancho ED, Luna C, Calero J (2012) New biofuel integrating glycerol into its composition through the use of covalent immobilized pig pancreatic lipase. Int J Mol Sci 13:10091-10112

14. Luna C, Sancho E, Luna D, Caballero V, Calero J, Posadillo A, Verdugo C, Bautista FM, Romero AA (2013) Biofuel that keeps glycerol as monoglyceride by 1,3-selective ethanolysis with pig pancreatic lipase covalently immobilized on $\mathrm{AlPO}_{4}$ support. Energies 6:3879-3900

15. Verdugo C, Luna D, Posadillo A, Sancho ED, Rodriguez S, Bautista F, Luque R, Marinas JM, Romero AA (2011) Production of a new second generation biodiesel with a low cost lipase derived from Thermomyces lanuginosus: optimization by response surface methodology. Catal Today 167:107-112

16. Xu YF, Wang QJ, Hu XG, Li C, Zhu XF (2010) Characterization of the lubricity of bio-oil/diesel fuel blends by high frequency reciprocating test rig. Energy 35:283-287

17. Haseeb A, Sia SY, Fazal MA, Masjuki HH (2010) Effect of temperature on tribological properties of palm biodiesel. Energy 35:1460-1464

18. Wadumesthrige K, Ara M, Salley SO, Ng KYS (2009) Investigation of lubricity characteristics of biodiesel in petroleum and synthetic fuel. Energy Fuels 23:2229-2234

19. Çelikten I (2011) The effect of biodiesel, ethanol and diesel fuel blends on the performance and exhaust emissions in a diesel engine. GU J Sci 24:341-346

20. Cheenkachorn K, Fungtammasan B (2009) Biodiesel as an additive for diesohol. Int J Green Energy 6:57-72

21. Jaganjac M, Prah IO, Cipak A, Cindric M, Mrakovcic L, Tatzber F, llincic P, Rukavina V, Spehar B, Vukovic JP, Telen S, Uchida K, Lulic Z, Zarkovic N (2012) Effects of bioreactive acrolein from automotive exhaust gases on human cells in vitro. Environ Toxicol 27:644-652

22. Pang XB, Mu YJ, Yuan J, He H (2008) Carbonyls emission from ethanol-blended gasoline and biodiesel-ethanol-diesel used in engines. Atmos Environ 42:1349-1358

23. Szczesna-Antczak M, Kubiak A, Antczak T, Bielecki S (2009) Enzymatic biodiesel synthesis - key factors affecting efficiency of the process. Renew Energy 34:1185-1194

24. Moayedallaie S, Mirzaei M, Paterson J (2010) Bread improvers: comparison of a range of lipases with a traditional emulsifier. Food Chem 122:495-499

25. Xu Y, Nordblad M, Woodley JM (2012) A two-stage enzymatic ethanol-based biodiesel production in a packed bed reactor. J Biotechnol 162:407-414 
26. Yara-Varon E, Joli JE, Torres M, Sala N, Villorbina G, Mendez JJ, CanelaGarayoa R (2012) Solvent-free biocatalytic interesterification of acrylate derivatives. Catal Today 196:86-90

27. Chang C, Chen JH, Chang CMJ, Wu TT, Shieh CJ (2009) Optimization of lipase-catalyzed biodiesel by isopropanolysis in a continuous packed-bed reactor using response surface methodology. N Biotechnol 26:187-192

28. Min JY, Lee EY (2011) Lipase-catalyzed simultaneous biosynthesis of biodiesel and glycerol carbonate from corn oil in dimethyl carbonate. Biotechnol Lett 33:1789-1796

doi:10.1186/s40643-014-0011-y

Cite this article as: Luna et al:: Production of a biodiesel-like biofuel without glycerol generation, by using Novozym 435, an immobilized Candida antarctica lipase. Bioresources and Bioprocessing 2014 1:11.

\section{Submit your manuscript to a SpringerOpen ${ }^{\circ}$} journal and benefit from:

- Convenient online submission

- Rigorous peer review

- Immediate publication on acceptance

- Open access: articles freely available online

- High visibility within the field

- Retaining the copyright to your article 